\title{
ESTILOS
}

DOI: https://doi.org/10.11606/issn.1981-1624.v24i2p358-370.

\section{Experiências institucionais}

\section{Acompanhamento para educadoras de bebês com deficiência em creche: relato de experiência}

\section{Tatiele Jacques Bossi; Cesar Augusto Piccinini}

Resumo. O presente estudo tem por objetivo descrever o Programa de Acompanhamento para Educadoras de Creche em Contexto Inclusivo - PROAECI e apresentar detalhes de sua implementação. Relata-se a aplicação do PROAECI a 3 educadoras de berçário em que tinha um bebê ( 24 meses) com deficiência física incluído nesta turma. O programa teve por objetivo oferecer uma escuta sensível e reflexiva sobre a relação das educadoras com o bebê com deficiência, acolhendo seus sentimentos, demandas e dificuldades. O PROAECI foi realizado em seis encontros, aplicados com periodicidade semanal e de forma individual, com duração de 50 minutos. Cada encontro tinha um tema específico norteado por conceitos da teoria winnicottiana, referentes às tarefas da educadora (holding, manuseio e apresentação de objetos) e competências da educadora (previsibilidade, adaptação ao saber materno e diagnóstico pedagógico). Destaca-se o potencial do PROAECI, ao sensibilizar as educadoras para desenvolver uma atitude reflexiva, acolhedora, ativa e responsável com o bebê com deficiência. Palavras-chave: educação inclusiva; educação infantil; programa de acompanhamento para educadoras; Winnicott.

\section{Acompañamiento para educadoras de bebés con discapacidad en un jardín infantil: relato de experiencia}

Resumen. El presente estudio tiene por objetivo describir el Programa de Acompañamiento para Educadoras de Jardín Infantil en Contexto Inclusivo - PROAECI y presentar detalles de su implementación. Se relata la aplicación del PROAECI a 3 educadoras de jardín infantil en que tenía un bebé (24 meses) con discapacidad física incluida. El programa tuvo por objetivo ofrecer una escucha sensible y reflexiva sobre la relación de las educadoras con el bebé con discapacidad, acogiendo sus sentimientos, demandas y dificultades. El programa se realizó a lo largo de seis encuentros, aplicados con periodicidad semanal y de forma individual, con una duración de 50 minutos. Cada encuentro tenía un tema específico orientado por conceptos de la teoría winnicottiana referentes a las tareas de la educadora (holding, manejo y presentación de objetos) y competencias de la educadora (previsibilidad, adaptación al saber materno y diagnóstico pedagógico). Se destaca el potencial del

1. Pós-doutoranda em Psicologia na Universidade Federal de Rio Grande do Sul, Porto Alegre, RS, Brasil. Email: tatielejbossi@gmail.com

2. Docente de Psicologia na Universidade Federal de Rio Grande do Sul, Porto Alegre, RS, Brasil. E-mail: piccinini@portoweb.com.br 
PROAECI, al sensibilizar a las educadoras para desarrollar una actitud reflexiva, acogedora, activa y responsable con el bebé con discapacidad.

Palabras clave: educación inclusiva; educación de la primera infancia; programa de acompañamiento para educadoras; Winnicott.

\title{
Monitoring for teachers of infants with disabilities in day care: report of experience
}

\begin{abstract}
The present study aims to describe the Monitoring Program for Day Care Teachers in an Inclusive Context - PROAECI and present details of its implementation. The application of PROAECI to 3 nursery teachers in which they had a baby ( 24 months) with physical disability included is reported. The purpose of the program was to offer a sensitive and reflexive listening on the relationship of the teachers toward the infant with disability, accepting their feelings, demands and difficulties. The program was conducted over six meetings, applied weekly and individually, lasting 50 minutes. Each meeting had a specific issue guided by Winnicott's concepts related to the tasks of the teacher (holding, handling and object-presenting) and competences of the teacher (predictability, respect to maternal knowledge and educational diagnosis). It highlights the potential of PROAECI, by sensitizing the teachers to develop a reflexive, welcoming, active and responsible attitude toward the infant with disability.
\end{abstract}

Keywords: inclusive education; early childhood education; monitoring program for teachers; Winnicott.

A

busca por creches tem apresentado crescimento expressivo nos últimos anos. Segundo o Observatório do Plano Nacional da Educação - PNE (2019), 30,4\% das crianças brasileiras de 0 a 3 anos estavam matriculadas em creche no ano de 2015. No entanto, a meta do governo federal é de que, até 2024, 50\% das crianças dessa faixa etária estejam matriculadas. Entre estas estão os bebês e as crianças com deficiência que tem o direito de serem incluídos em escolas regulares, ao invés de escolas especiais (Brasil, 2015).

De acordo com o Censo de 2010 (SDH/PR, 2012), 2,8\% da população entre 0 e 4 anos possui algum tipo de deficiência auditiva, visual, motora e/ou intelectual. Os dados do Instituto Nacional de Estudos e Pesquisas Educacionais Anísio Teixeira - INEP (2014) apontam que em 2013 houve um aumento de 6,2\% de matrículas na educação infantil entre crianças com deficiência na faixa etária de 0 a 5 anos, quando comparado ao ano anterior. Já no período compreendido entre 2007 e 2013 o aumento foi na ordem de 42\%, e deve seguir aumentando nos próximos anos ao se considerar a política nacional de inclusão.

Essa temática é ainda mais relevante ao se considerar os grandes desafios que o país enfrenta na implementação de um atendimento de qualidade em creches e pré-escolas. Tal atendimento deve considerar a complementariedade entre o cuidar e o educar, uma vez que, na educação infantil, cuidando se educa, e ao educar também se produz um ato de cuidado (Menezes, Carvalho \& Filho, 2016; Santos, Santos, Costa \& Silva, 2015). Assim, há uma interdependência dos aspectos emocionais, cognitivos, sociais e físicos, e as atividades pedagógicas nas turmas de berçário (0 a 24 meses) devem contemplar as demandas dos bebês, visando o seu processo de desenvolvimento. Nesse sentido, frente à complexidade do cuidar e do educar na educação infantil, é plausível supor que a presença de deficiência pode trazer um componente adicional para a relação educadora-bebê, que por vezes dificulta a identificação das demandas do bebê. Ou ainda exige da educadora determinadas capacidades para atendêlo, a fim de acolhê-lo em suas particularidades, o que pode impactar na qualidade do processo inclusivo (Alves, 2018; Siddiqua \& Janus, 2017; Souza \& Minetto, 2017).

Nessa direção, é necessário destacar que a creche é um importante espaço de constituição do psiquismo dos bebês e crianças pequenas (Bossi \& Piccinini, 2018; Pessôa; Seidl-deMoura, Ramos \& Mendes, 2016). E, para se pensar o desenvolvimento emocional do bebê no 
contexto da relação educadora-bebê, é possível se recorrer aos conceitos de Winnicott (1965/1993), como os de holding (segurar ou sustentação), manuseio (handling) e apresentação de objetos (object-presenting), mesmo que originalmente tenham sido usados para descrever as relações iniciais mãe-bebê.

O holding (Winnicott, 1965/1993) se refere à rotina de cuidados oferecidos ao bebê, e nele se inclui, principalmente, o segurar físico. Essa tarefa tem relação direta com a capacidade da mãe (ou substituta, como a educadora) de se identificar com o bebê a fim de lhe oferecer o que ele necessita. Essa capacidade de oferecer o holding suficientemente bom permite que o bebê adquira a tarefa básica de integração (Winnicott, 1965/1993), possibilitando que com o tempo o bebê passe a ter uma personalidade mais integrada, percebendo-se como uma unidade.

Já o manuseio diz respeito à forma como a mãe manipula o corpo do bebê. Segundo Winnicott (1945/2000) o manuseio faz parte do holding, mas se refere aqueles cuidados a nível de pele, como a delicadeza ao banhar o bebê, o cuidado em mantê-lo aquecido, a suavidade dos abraços e das carícias. Esses cuidados possibilitariam a delimitação da estrutura corporal do bebê e o estabelecimento do sentimento de estar dentro do próprio corpo, ou seja, a tarefa básica de personalização.

Por fim, a apresentação de objetos permite ao bebê desenvolver a capacidade de relacionar-se com os objetos, sejam eles subjetivos ou objetivos (Winnicott, 1965/1993). No início de sua vida, o bebê não possui maturidade suficiente que lhe capacite a perceber a realidade externa. Essa conquista só é possível se a mãe apresentar o mundo ao bebê de maneira adequada, impulsionando-o nas suas descobertas do mundo externo. A sensibilidade da mãe em atendê-lo em suas demandas específicas sustenta a sua ilusão de onipotência, o que o possibilita ter a fantasia de que cria o mundo (mãe) que o cuida e atende suas demandas. Na medida em que o bebê progride no processo de amadurecimento, torna-se capaz de suportar pequenas frustrações, o que permite à mãe não exercer mais uma adaptação perfeita as suas necessidades. Dessa forma, o bebê começa a desenvolver a consciência de que o mundo já estava pronto para ser criado por ele (Winnicott, 1965/1993).

As tarefas de cuidado materno, destacadas acima, são possibilitadas pelas competências que as mães possuem (e cuidadores substitutos) e conseguem utilizar no momento de contato com o bebê. Segundo Winnicott (1988/1990), inicialmente, a adaptação da mãe às necessidades do bebê deve ser praticamente absoluta, o que se traduz como a previsibilidade dos cuidados maternos. Essa capacidade de adaptação decresce à medida que a integração torna-se mais consistente e o bebê adquire meios de lidar com suas frustrações, mas estas precisam ser na medida do suportável para ele. A previsibilidade continua sendo necessária, já que o bebê precisa saber que a mãe vai faltar por um período curto de tempo e vai retornar para atendê-lo antes que a demanda se torne insuportável. Nesse sentido, a previsibilidade envolve a sensibilidade da mãe em ser empática ao que o bebê necessita e em respeitar o seu ritmo próprio, não se tornando um ambiente intrusivo.

Além dessas tarefas e competências maternas, que obviamente se estendem aos cuidadores substitutos, Winnicott (1936/1997) ressaltou algumas competências específicas das professoras de educação infantil, que seriam importantes para o desenvolvimento emocional dos bebês. Uma dessas competências se refere à capacidade da educadora de se adaptar ao saber materno. Isso porque, apesar de a educadora ter de exercer as funções maternas junto aos bebês, como as destacadas acima, é fundamental que ela não confunda o seu papel com o papel da mãe, ou seja, ela deve ter consciência de que não é a mãe daquele bebê. Isso 
possibilita, inclusive, a boa relação entre as educadoras e a família da criança, no sentido de que a escola deve respeitar a autoridade das mães e dos pais e o conhecimento que eles têm sobre os filhos, sem sobrepor-se a eles.

Além disso, ao considerar que a mãe suficientemente boa é aquela que se adapta intuitivamente às necessidades do bebê (Winnicott, 1966/1988), o mesmo pode ser estendido para a equipe da creche em que, independentemente da formação específica que tenha cada educadora, ela pode contribuir satisfatoriamente nos cuidados dos bebês. No entanto, um bom conhecimento sobre o desenvolvimento e a psicologia infantil pode possibilitar o que Winnicott (1957/1982) chamou de diagnóstico pedagógico. Segundo ele, a escola maternal pode agir preventivamente com relação à saúde da criança, bem como contribuir para o processo de amadurecimento do bebê, ao estar atenta aos aspectos emocionais envolvidos no processo de cuidar e de educar. Esse aspecto torna-se ainda mais relevante ao considerarmos os bebês com deficiência. Isso porque, para além do que seria esperado que as educadoras fizessem frente a um bebê sem deficiência, no presente caso elas precisam também conhecer e identificar o que é característico da deficiência de determinado bebê e eventuais implicações para o seu desenvolvimento e para sua relação com a educadora e com os colegas. Vale ressaltar que, para Winnicott (1957/1982), não cabe à educadora estabelecer o diagnóstico pedagógico no sentido de classificar alguma psicopatologia nos bebês. O que lhe é devido é a capacidade de ficar atenta ao seu aluno e saber identificar algo que não se configura como o esperado para aquela etapa do desenvolvimento, a fim de poder oferecer as práticas pedagógicas adequadas e os encaminhamentos necessários.

Apesar das ideias inovadoras e ainda atuais de Winnicott (1957/1982), elas não têm se apresentado na educação infantil, e nem em estudos de intervenções em creches junto a educadoras de bebês, mesmo em contextos de inclusão, onde a relação educadora-bebê com deficiência pode apresentar demandas mais particulares. Além disso, os estudos que ressaltam a educação infantil tendem a focar a inclusão na faixa etária entre 3 e 6 anos de idade (Oliveira, 2016; Rodrigues, 2017; Sucuoglu, Bakkaloglu, Karasu, Demir \& Akalin, 2014), e em menor número no primeiro ou segundo ano de vida (Bossi, Junges \& Piccinini, 2018; Drago \& Dias, 2017; Vitta, 2010). Na verdade, raros são os estudos que abordam a inclusão dos bebês com deficiência nas turmas de berçário (Bossi et al., 2018; Vitta, 2010). E também são escassos os estudos com propostas de acompanhamento e intervenções com educadoras de bebês com deficiência que possam oferecer reflexões para melhorar a qualidade do processo inclusivo e da relação educadora-bebê com deficiência (Biglan, Layton, Jones, Hankins \& Rusby, 2013; Soares, 2011).

Considerando o exposto, é plausível se pensar que programas de acompanhamento para as educadoras com base em conceitos winnicottianos podem ser relevantes, particularmente no contexto de inclusão de bebês com deficiência. No entanto, qualquer programa de acompanhamento destinado às educadoras deve ser construído a partir do saber compartilhado entre a educadora e o(a) profissional que o aplica, premissa que pauta o Programa de Acompanhamento para Educadoras de Creche em Contexto Inclusivo - PROAECI (Bossi \& Piccinini, 2015). Diante disso, o presente relato de experiência tem por objetivo descrever as bases teóricas winnicotianas do PROAECI e apresentar detalhes de sua implementação.

\section{Método: descrição e implementação do PROAECI}


O PROAECI é um programa de acompanhamento para educadoras de creche que atendem bebês com deficiência em contexto inclusivo, que foi desenvolvido como parte de um projeto de pesquisa e extensão denominado "A inclusão de bebês com deficiência em creche: programa de intervenção para educadoras com base em conceitos winnicottianos" (Bossi \& Piccinini, 2015) desenvolvido para a tese de doutorado da primeira autora (Bossi, 2017). Tem por finalidade oferecer uma escuta sensível e reflexiva sobre a relação e as experiências das educadoras com o bebê com deficiência, acolhendo seus sentimentos, demandas e dificuldades, o que contribui para que as educadoras também sejam acolhedoras, ativas e responsáveis com o bebê. Por isso, ele é baseado em conceitos da teoria de Winnicott (1965/1993), tendo em vista o interesse teórico dos autores do presente estudo e a experiência na área de desenvolvimento infantil. Os conceitos winnicottianos, embora originalmente tenham como foco a relação mãe-bebê, apresentam-se como promissores no contexto de relação educadora-bebê, visto que possibilitam refletir sobre as tarefas das educadoras para com o bebê com deficiência (holding, manuseio e apresentação de objetos) e sobre suas competências como educadoras (previsibilidade, adaptação ao saber materno e diagnóstico pedagógico).

O PROAECI está organizado em seis encontros realizados individualmente, com duração de 50 minutos e periodicidade semanal. Tendo em vista que os encontros foram realizados no horário de trabalho das educadoras e nas dependências da creche, respeitaram-se os horários da instituição e a dinâmica de funcionamento da mesma. A partir de um posicionamento de escuta receptiva e flexível da pesquisadora eram estabelecidos momentos de diálogo e reflexão com a educadora sobre seus conhecimentos, práticas, dúvidas e sentimentos associados a cada temática que era abordada. Ao mesmo tempo buscava-se sensibilizá-las para as demandas do bebê, com base na perspectiva winnicottiana.

Em cada encontro se priorizava um tema específico para que as educadoras pudessem refletir sobre os conteúdos tratados, junto com a pesquisadora. No primeiro encontro, era apresentado, brevemente, o objetivo do PROAECI e eram feitas combinações a respeito de sua implementação e dinâmica. Na sequência, era introduzido para a educadora o tema foco do encontro. Após, abria-se espaço para a educadora manifestar-se, trazendo suas experiências e reflexões sobre o tema. Ao final, era solicitado que, ao longo da semana de interação com o bebê com deficiência, ela pudesse refletir sobre o tema trabalhado, e que trouxesse suas reflexões e experiências para discussão no próximo encontro. A partir do segundo encontro em diante, sempre se iniciava escutando as reflexões e experiências da educadora, com base no que havia sido tratado no encontro anterior e, após isso, apresentavase o tema foco do encontro, seguindo a dinâmica descrita acima. Os seis encontros têm como foco os seguintes temas, detalhados em profundidade em Bossi (2017):

(1) A creche e o desenvolvimento emocional do bebê com deficiência: este encontro teve por objetivo dialogar com a educadora sobre o desenvolvimento emocional do bebê com deficiência e sobre a importância da educadora e da creche como ambiente facilitador deste desenvolvimento;

(2) Necessidades, potencialidades e limitações do bebê com deficiência: teve por objetivo dialogar com a educadora sobre as necessidades, potencialidades e limitações do bebê com deficiência na creche;

(3) Exploração dos espaços e objetos da creche pelo bebê com deficiência: teve por finalidade dialogar com a educadora sobre a importância dos espaços e dos objetos da creche 
serem organizados de acordo com as necessidades e demandas dos bebês, em particular do bebê com deficiência;

(4) Potencialidades da educadora junto ao bebê com deficiência: este encontro objetivou dialogar com a educadora sobre suas potencialidades junto ao bebê com deficiência;

(5) Sentimentos despertados pelos bebês com deficiência: teve por finalidade dialogar sobre os sentimentos da educadora despertados pelo bebê com deficiência; e,

(6) A creche e a família do bebê com deficiência: este encontro teve por objetivo dialogar com a educadora sobre sua relação com a família do bebê com deficiência.

Todos os encontros foram gravados em áudio, a fim de serem transcritos e analisados. Ainda, foi realizado um registro escrito sobre as impressões e sentimentos da pesquisadora suscitados durante os mesmos, o que também foi considerado para fins de análise do PROAECI.

\section{Resultados e discussão}

Para o presente estudo foram consideradas todas as transcrições dos encontros com três educadoras participantes do PROAECI, que foram analisadas qualitativamente. Em função do limite de páginas deste relato de experiência, apresenta-se, a seguir, apenas uma síntese de alguns dos principais achados dos casos que, originalmente, na tese de Bossi (2017), foram descritos a partir do relato clínico. O relato clínico é comumente utilizado na clínica psicanalítica e permite uma escrita mais livre, rica em detalhes verbais e não verbais e que contempla uma interpretação e uma tradução dos dados à luz da teoria (Epstein, 2011).

Para fins de apresentação, as educadoras serão chamadas de Alice (33 anos), Rafaela (28 anos) e Luciane (32 anos) que atendiam a Manuela (24 meses), que apresentava deficiência física e estava incluída na turma de berçário de uma Escola Municipal de Educação Infantil EMEI de Porto Alegre. A deficiência de Manuela se caracterizava por uma alteração generalizada do tônus muscular de tronco e membros, que a impedia de equilibrar o corpo e conseguir caminhar. Todas as educadoras eram concursadas e exerciam a função de professoras. A educadora Alice tinha formação em educação física licenciatura e trabalhava quatro horas diárias na instituição. Já as educadoras Rafaela e Luciane eram graduadas em pedagogia e trabalhavam oito horas diárias na EMEI.

Winnicott (1965/1993) destacou que o bebê nasce com um potencial inato e herdado rumo ao crescimento e ao desenvolvimento pessoal. No entanto, esse potencial só entra em cena quando o bebê encontra um ambiente facilitador, que se adapta às suas necessidades, de acordo com seu nível de desenvolvimento. Examinando conjuntamente os três casos do presente estudo, foi possível identificar algumas particularidades entre as educadoras que participaram do PROAECI. Duas delas (Alice e Luciane) conseguiam servir como ambiente facilitador para o desenvolvimento de Manuela, uma vez que a estimulavam em suas explorações e evoluções em seu desenvolvimento motor, na direção do esperado com base no conceito de apresentação de objetos (Winnicott, 1965/1993). Foi possível perceber uma boa relação entre educadora-bebê nesses dois casos, de modo que o segurar físico dispensado a bebê em seus cuidados diários também representava um segurar emocional (i.e. holding), que possibilitava a ela confiar nas educadoras a fim de se aventurar em seu desenvolvimento. Assim, essa relação característica da "educadora suficientemente boa", parafraseando Winnicott (1965/1993), parece que já estava presente nestes dois casos e foi fortalecida ao 
longo do PROAECI, através de uma maior sensibilização dessas educadoras frente às demandas do bebê.

Já com a outra educadora (Rafaela) puderam-se identificar dificuldades nessa relação educadora-bebê, muito provavelmente influenciado por diversas questões pessoais, como seu cansaço e aparente esgotamento emocional, frente às dificuldades relatadas sobre o seu trabalho na escola pública. Tal aspecto coloca a importância de se considerar o bem-estar psicológico da educadora como impactando na qualidade do processo inclusivo (Biglan et al., 2013). Isso fazia com que ela se queixasse das muitas exigências do bebê, que por vezes nem sequer estavam relacionadas à deficiência dele, mas sim a aspectos e a demandas próprias do desenvolvimento típico de um bebê, naquela faixa etária. Nesse sentido, Winnicott (1957/1982) ressaltou que as educadoras deveriam ter um bom conhecimento sobre desenvolvimento infantil, a fim de identificar quando algo não estava indo bem, o que remete ao conceito de diagnóstico pedagógico. Rafaela demonstrava ter certo conhecimento sobre desenvolvimento infantil, mas parece que não conseguia aplicá-lo no caso de Manuela. No entanto, ao final do PROAECI ela pareceu mais sensível e mais vinculada à Manuela, inclusive se questionando se não deveria estar mais disponível para ela (i.e. holding). Tais conquistas permitem que as relações estabelecidas na creche tenham impacto favorável no psiquismo dos bebês (Bossi \& Piccinini, 2018; Pessôa et al., 2016), em especial de Manuela.

As educadoras também destacaram que não havia tantas diferenças relativas a atender Manuela, quando comparado aos bebês sem deficiência, tendo em vista as necessidades individualizadas de todos. Tal aspecto remete à literatura que destaca a importância da educadora acolher as individualidades de todos os bebês e, em particular neste estudo, as do bebê com deficiência (Alves, 2018; Siddiqua \& Janus, 2017; Souza \& Minetto, 2017). Nesse sentido, elas ressaltaram, muitas vezes, as necessidades do bebê decorrentes de sua deficiência física, que implicava em limitação motora para caminhar. Tal aspecto demandava mais atenção por parte das educadoras, o que, por vezes, gerava maior cansaço físico nelas. Todas as educadoras também destacaram a maior necessidade de atenção que deveria ser dada ao bebê em decorrência de, por vezes, em suas explorações, ele se colocar em risco. Isso se dava, principalmente, nos brinquedos mais altos visto que ele ainda não tinha a mesma mobilidade que os demais bebês da turma, o que corrobora a literatura apresentada com relação à inclusão de crianças com deficiência física (Melo \& Ferreira, 2009). No entanto, ressaltaram essa curiosidade e capacidade de exploração de Manuela como uma potencialidade dela. E não pareceram limitar as suas explorações e brincadeiras, oferecendo apenas os limites necessários a fim de manter a sua segurança, o que remete ao conceito winnicottiano de apresentação de objetos (Winnicott, 1965/1993). Cabe ressaltar que esta foi uma tarefa que todas as educadoras desempenhavam como o esperado, de modo que o PROAECI referendou essa capacidade já existente na relação educadora-bebê. Tal tarefa da educadora parece ser característica do ambiente de creche, visto que naturalmente implica em a criança sair da relação dual mãe-bebê e, assim, adentrar em outro ambiente de socialização e, com isso, se impulsionar nas suas descobertas no mundo externo.

Uma das educadoras (Alice) destacou que, tanto em termos gerais, como em termos materiais, a escola apresentava-se como adequada a fim de estimular o desenvolvimento de Manuela. Inclusive ressaltou a organização dos espaços e do mobiliário como possibilitando a ela uma maior independência (ex. bancos no saguão, que permitiam a ela se apoiar e caminhar). Da mesma forma, outra educadora (Luciane) considerou a escola propícia para o bebê com deficiência. Inclusive, ressaltou que o ambiente da escola, como estava organizado, 
possibilitava a Manuela se aventurar no seu desenvolvimento, impulsionando suas evoluções motoras, o que parecia favorecer sua inclusão. Tais aspectos remetem ao conceito winnicottiano de previsibilidade (Winnicott, 1988/1990) uma vez que a escola, enquanto ambiente previsível, possibilitava a Manuela saber onde e de que forma poderia se arriscar em suas descobertas. Do mesmo modo, as educadoras não limitavam suas explorações e também se mantinham previsíveis para ela, em sua forma de agir e de lhe oferecer os auxílios necessários quando demandava.

A principal diferença nos relatos das educadoras se deu, mais uma vez, com relação à outra professora (Rafaela), que destacou a escola como não adaptada para os bebês no berçário, por possuir mobiliário e brinquedos compatíveis a crianças maiores. Esta era uma queixa legítima e que demonstrava a sua sensibilidade quanto ao bem-estar e especificidades do desenvolvimento dos bebês. No entanto, ela reconheceu que isso favorecia o desenvolvimento e a inclusão de Manuela, visto que os móveis mais altos possibilitavam a ela se apoiar e caminhar, sem demandar a ajuda das educadoras. Pensando na escola pública e nas dificuldades da mesma em se adaptar para atender os bebês em geral, e os bebês com deficiência em particular, em termos de acessibilidade, a possibilidade de utilizar os recursos já disponíveis a fim de favorecer o desenvolvimento de Manuela é algo que merece ser elogiado. No entanto, isso não significa que críticas quanto à ausência de recursos materiais não devam ser feitas, visto que tais aspectos tendem a impactar na qualidade do processo inclusivo (Bossi et al., 2018), uma vez que as particularidades específicas dos bebês pareciam não ser contempladas, para além dos aspectos da deficiência de Manuela.

Além disso, a análise dos três casos investigados neste estudo permite ressaltar que as educadoras destacaram a importância do processo inclusivo ocorrer. Tal aspecto também apareceu no estudo de Zucchetti (2011) o que sinaliza que, apesar das dificuldades enfrentadas, as educadoras ainda priorizam garantir os direitos das crianças. No entanto, para uma delas (Rafaela), a escola não oferecia as condições apropriadas para essa inclusão, como a presença de um profissional de apoio e os recursos materiais adequados. Isso, somado a relação frágil estabelecida entre ela e o bebê com deficiência, dificultava que ela apresentasse, na relação educadora-bebê, as potencialidades da educadora traduzidas nos conceitos holding e manuseio, visto que ela tinha dificuldades em atender as demandas do bebê relacionadas à deficiência (ex. ajuda na locomoção) ou a sua condição de bebê (ex. demanda por colo). Isso foi se modificando, pelo menos em parte, ao longo do PROAECI, quando ela passou a perceber a necessidade de se vincular mais a Manuela. Nesse caso, ficou mais explícito o quanto cuidar e educar uma criança com deficiência acaba sendo emocionalmente exigente para a educadora, por demandar determinadas especificidades na relação educadora-bebê (Siddiqua \& Janus, 2017; Souza \& Minetto, 2017).

Foi também possível identificar, no discurso das educadoras, sentimentos de insegurança, como os ressaltados na literatura (Vitta, 2010), no momento inicial de contato com o bebê, devido ao desconhecimento de sua deficiência e sobre a melhor forma de proceder frente as suas estimulações. À medida que as educadoras conheceram Manuela, tais sentimentos foram substituídos pela satisfação em verem suas evoluções motoras e sentirem que colaboraram para que isso ocorresse. Inclusive, uma das educadoras (Luciane) ressaltou que, à medida que se tornou mais sensível para com Manuela e com um olhar diferenciado frente as suas demandas, se percebia com um sentimento de maior responsabilidade perante ela (i.e. holding e manuseio). Já outra educadora (Rafaela), a partir de suas reflexões, sentiu que se diferenciava das demais colegas, visto ter demonstrado menor empolgação frente às 
evoluções desenvolvimentais do bebê. Tal fato a fez perceber-se pouco disponível emocionalmente, o que a impulsionou a pensar na sua relação com Manuela, e se permitiu ficar mais sensível a ela, apresentando, assim, uma melhora na capacidade de holding e manuseio (Winnicott, 1965/1993).

As evidências que apareceram entre os três casos investigados neste estudo também permitem ressaltar particularidades com relação ao tema da família e da creche no contexto investigado. Duas educadoras (Alice e Luciane) se mostraram muito respeitosas com relação à mãe de Manuela, ressaltando suas potencialidades e sua disponibilidade em levá-la nos atendimentos que a filha necessitava. Inclusive, o olhar de atenção e preocupação dessas educadoras frente ao bebê parece ter a incentivado a mudar o próprio olhar frente à filha, o que possibilitou se vincular mais a ela, reconhecer sua deficiência e procurar ajuda. Tal aspecto refere-se ao conceito winnicottiano de adaptação ao saber materno (Winnicott, 1936/1997) visto que através de uma postura respeitosa e que considerava o saber da mãe (ou falta dele) frente sua filha, as educadoras conseguiram mostrar que ela precisava de atendimento especializado, a fim de estimular seu desenvolvimento. As educadoras, inclusive, solicitaram o auxílio da mãe, sem imposições, e permitiram a ela participar do processo inclusivo de sua filha, configurando-se como agente da inclusão. Tal parceria entre família e escola tem sido ressaltada na literatura como uma prática que favorece o reconhecimento das necessidades do bebê com deficiência em seus diferentes contextos de desenvolvimento (Cummings, Sills-Busio, Barker \& Dobbins, 2015).

No entanto, outra educadora (Rafaela) apresentou um olhar diferenciado perante essa mãe, se apegando ao fato de que, antes da entrada na escola, ela não havia procurado os atendimentos adequados para Manuela. Isso a impossibilitava de reconhecer o grande movimento que a mãe fazia frente a esse aspecto. Ao longo do PROAECI ela não pareceu conseguir desenvolver essa competência relacionada à adaptação ao saber materno, o que permite pensar que, com Rafaela, o número de encontros precisaria ser ampliado, a fim de impulsioná-la em suas reflexões frente à relação mãe-educadora.

Nesse sentido, cabe ressaltar que ao longo dos seis encontros do PROAECI, as educadoras puderam refletir sobre sua prática e sobre sua relação com Manuela. Todas demonstraram evoluções quanto a este aspecto, apesar de suas diferenças pessoais, de modo que se mostraram mais conectadas a Manuela e mais sensíveis às suas demandas específicas colocadas pela deficiência. Por alguns momentos, mostraram-se sobrecarregadas com a rotina e os cuidados de um bebê com necessidades mais diferenciadas, de modo que o espaço de escuta oferecido para acolher essas angústias, comumente pouco consideradas no contexto escolar, mostrou-se importante, e pareceu favorecer a relação educadora-bebê.

Cabe ainda ressaltar que o PROAECI, de certo modo, veio sanar uma defasagem de propostas de acompanhamento e de intervenção com educadoras de bebês com deficiência em creche. Principalmente, aquelas que propõem abrir um espaço para escuta e reflexão que permita sensibilizar as educadoras frente às demandas de cuidado do bebê com deficiência, visando melhorar a qualidade da relação educadora-bebê contribuindo, assim, para o processo inclusivo (Biglan et al., 2013; Soares, 2011).

Além disto, a utilização da abordagem winnicottiana como norteadora dos encontros do PROAECI mostrou-se promissora, apesar de Winnicott não ter se aprofundado no estudo e na intervenção junto a crianças com deficiência. No entanto, ele deixou explícito, ao longo de sua obra, que poderia haver particularidades na relação mãe-bebê quando alguma imperfeição física ou funcional se fizesse presente na criança (Winnicott, 1971/1984) mantendo, assim, 
um caminho aberto para pesquisas e intervenções na área. Da mesma forma, ele voltou sua atenção aos aspectos referentes à relação mãe-bebê, e não se aprofundou na temática da relação educadora-bebê. Mas mesmo assim não deixou de destacar a importância das educadoras frente ao desenvolvimento infantil, no sentido de que também deveriam exercer funções maternas, oportunizando a criança vivenciar a escola como uma extensão do lar (Winnicott, 1957/1982). Nesse sentido, pode-se pensar que Winnicott já considerava o cuidar e o educar como algo indissociável na educação infantil, como destaca a literatura mais recente (Menezes, et al., 2016; Santos et al., 2015). Ao considerar a sociedade ocidental atual, em que os bebês são inseridos na creche ainda nos primeiros meses de vida e lá permanecem até a entrada na pré-escola, tal colocação de Winnicott faz-se atual e relevante.

Essas duas sugestões de Winnicott, referentes à relação mãe-bebê com deficiência e a relação educadora-bebê, embasaram a proposta do PROAECI. Com isso, seus conceitos referentes às funções maternas puderam ser estendidos às educadoras de creche em contexto inclusivo, principalmente as tarefas da educadora (holding, manuseio e apresentação de objetos) e as competências da educadora (previsibilidade, adaptação ao saber materno e diagnóstico pedagógico). Assim sendo, esses conceitos podem ser considerados, de certo modo, como padrões da qualidade da ação pedagógica das educadoras e referência de ambiente educacional na educação infantil, particularmente no contexto inclusivo. Cabe salientar ainda que, no presente estudo, os conceitos winnicottianos, embora definidos separadamente para fins didáticos, na prática ganham outros contornos, visto que se intercalam na sua dinamicidade. Por isso, não devem ser vistos como categorias independentes e excludentes, mas sim como inter-relacionados, que juntos favorecem a qualidade da relação educadora-bebê.

Por fim, cabe destacar que três semanas após a finalização da intervenção foi realizada uma entrevista de avaliação da mesma. As educadoras consideraram a experiência com o PROAECI como importante e passaram, também, a se preocupar em refletir e em auto avaliar sua relação com Manuela. Todas mencionaram que gostaram da dinâmica do PROAECI com um tema direcionado em cada encontro. No entanto, salientaram as dificuldades relacionadas ao terem de utilizar o horário de trabalho para participarem da intervenção. Isso permite pensar que os encontros poderiam funcionar melhor em um momento fora da jornada de trabalho das educadoras, o que exigiria arranjos com cada instituição.

\section{Considerações finais}

As evidências revelam os benefícios do PROAECI para as três educadoras participantes do estudo, mesmo considerando as diferenças pessoais e de relação com o bebê com deficiência. Trata-se de uma proposta pioneira, tanto por focar a inclusão de bebês na educação infantil, como por trazer a abordagem winnicotiana para este contexto. A educação infantil se constitui em uma porta de entrada do bebê em inclusão, e o atendimento à faixa etária de 0 a 24 meses precisa do oferecimento de um cuidado afetivo e estimulador do desenvolvimento do bebê com deficiência. No entanto, para que isso ocorra, é necessária uma relação adequada da educadora com o bebê, que possibilite o exercício das tarefas e das competências da educadora, entre elas as preconizadas por Winnicott (1965/1993) e destacadas neste estudo. Dessa forma, entende-se a inclusão na educação infantil como um processo que é construído na relação educadora-bebê com deficiência, visto que essa relação deve se dar, não com a 
deficiência do bebê, mas sim com o bebê, que tem as necessidades de todo e qualquer bebê e algumas especificidades impostas pela deficiência.

Cabe salientar que, na proposta do PROAECI, a tarefa da pesquisadora foi a de escutar e refletir com as educadoras sobre suas experiências com o bebê com deficiência, fazendo questionamentos, apontamentos e esclarecimentos, sempre no sentido de sensibilizá-la para as demandas do bebê a partir da abordagem winnicottiana. Dessa forma, buscava-se oferecer as educadoras uma escuta sensível e reflexiva sobre suas experiências, que acolhesse seus sentimentos, demandas e dificuldades na relação com este bebê, o que contribuiria para que elas também fossem acolhedoras, ativas e responsáveis com o bebê com deficiência.

Por fim, ressalta-se que, embora o PROAECI tenha sido aplicado para educadoras de bebê com deficiência física, é plausível se pensar que ele possa ser considerado no contexto de outras deficiências. Dessa forma, ampliam-se as possibilidades de sua aplicação para um público mais amplo no contexto da educação infantil que demanda por intervenções na área.

\section{Referências}

Alves, F. F. P. (2018). A inclusão das crianças com deficiência na Educação Infantil: Processo em construção. Educação, 41(2), 270-279. doi: 10.15448/1981-2582.2018.2.26786

Biglan, A., Layton, G. L., Jones, L. B., Hankins, M., \& Rusby, J. C. (2013). The value of workshops on psychological flexibility for early childhood special education staff. Topics Early Childhood Special Education, 32(4), 1-23. doi:10.1177/0271121411425191

Bossi, T.J. (2017). Inclusão de bebê com deficiência física em creche: programa de acompanhamento para educadoras com base em conceitos winnicottianos. Tese de Doutorado, Instituto de Psicologia, Universidade Federal do Rio Grande do Sul, Porto Alegre, RS.

Bossi, T.J. \& Piccinini, C. A. (2015). A inclusão de bebês com deficiência em creche: programa de intervenção para educadoras com base em conceitos winnicottianos. Projeto de pesquisa não publicado, Instituto de Psicologia, Universidade Federal do Rio Grande do Sul, Porto Alegre, RS.

Bossi, T.J. \& Piccinini, C. A. (2018). Maternal experience of the separation-individuation process in infants who attended or did not attend daycare. Trends in Psychology, 26(4), 2047-2062. doi: 10.9788/TP2018.4-12En

Bossi, T. J., Junges, A. P. P., \& Piccinini, C. A. (2018). Fatores que interferem no processo de inclusão de bebês com deficiência física no berçário. Psicologia Escolar e Educacional, 22(2), 377-384. doi: 10.1590/2175-35392018011348

Brasil (2015). Lei $N^{o}$ 13.146, de 6 de julho de 2015. Institui a Lei Brasileira de Inclusão da Pessoa com Deficiência (Estatuto da Pessoa com Deficiência). Brasília: Senado Federal. Texto recuperado em 10 jan. 2018: http://www.planalto.gov.br/ccivil_03/_ato2015-2018/2015/lei/113146.htm

Cummings, K. P., Sills-Busio, D., Barker, A. F., \& Dobbins, N. (2015). Parent-Professional partnerships in early education: Relationships for effective inclusion of students with disabilities. Journal of Early Childhood Teacher Education, 36(4), 309-323. DOI: 10.1080/10901027.2015.1105329

Drago, R., \& Dias, I. R. (2017). O bebê com síndrome de Down na educação infantil: Um estudo de caso. Revista Educação Especial, 30(58), 515-528. doi: 10.5902/1984686X24260

Epstein, R. (2011). El relato y la realidad. In: Asociacion Psicoanalítica de Buenos Aires - XXXIII Simposio Anual: relatos de la clínica (pp.240-246). Buenos Aires.

Instituto Nacional de Estudos e Pesquisas Educacionais Anísio Teixeira - INEP (2014). Censo escolar da educação básica 2013 - Resumo técnico. Brasília: O Instituto. Texto recuperado em 20 mar. 
2018:

http://download.inep.gov.br/educacao_basica/censo_escolar/resumos_tecnicos/resumo_tecnico_cen so_educacao_basica_2013.pdf

Melo, F. R. L. V., \& Ferreira, C. C. A. (2009). O cuidar do aluno com deficiência física na educação infantil sob a ótica das professoras. Revista Brasileira de Educação Especial, 15(1), 121-140. doi: $10.1590 /$ S1413-65382009000100009

Menezes, L. A., Carvalho, D. A. B., \& Filho, N. T. (2016). Um olhar sobre o cuidar e o educar na educação infantil. Educação \& Linguagem, 3(1), 32-44.

Observatório do PNE (2019). Educação infantil. Texto recuperado em 15 abr. 2019: http://www.observatoriodopne.org.br/indicadores/metas/1-educacao-infantil/indicadores

Oliveira, T. C. (2016). Práticas pedagógicas inclusivas no cotidiano da educação infantil na Escola de Aplicação da Universidade Federal do Pará. Dissertação de Mestrado, Instituto de Ciências da Educação, Universidade Federal do Pará, Belém, PA.

Pessôa, L. F., Seidl-de-Moura, M. L., Ramos, D. de O., \& Mendes, D. M. L. F. (2016). Sistemas de cuidados e o discurso de diferentes cuidadores do Rio de Janeiro: Evidências de trajetória de desenvolvimento. Estudos de Psicologia, 33(1), 71-82. DOI:10.1590/1982-02752016000100008

Rodrigues, P. R. E. (2017). Educação inclusiva: significados e sentidos configurados a partir de uma experiência formativa docente. Dissertação de Mestrado, Instituto de Educação, Universidade Federal de Alfenas, Alfenas, MG.

Santos, C. O. D., Santos, L. C., Costa, J. D., \& Silva, C. L. C. (2015). A indissociabilidade de cuidar e educar na educação infantil: um olhar sobre a modalidade creche. Ciências Humanas e Sociais, 3(1), 213-226.

Secretaria de Direitos Humanos da Presidência da República - SDH/PR (2012). Cartilha do Censo 2010: pessoas com deficiência. Brasília. Texto recuperado em 05 nov. 2016: http://www.portalinclusivo.ce.gov.br/phocadownload/cartilhasdeficiente/cartilha-censo-2010pessoas-com-deficiencia.pdf

Siddiqua, A., \& Janus, M. (2017). Experiences of parents of children with special needs at school entry: A mixed method approach. Child: Care, Health and Development, 43(4), 566-576. doi: 10.1111/cch.12443

Soares, C. F. (2011). As diferenças no contexto da educação infantil: estudo da prática pedagógica. Tese de doutorado, Faculdade de Educação, Universidade Federal do Ceará, Fortaleza, CE.

Souza, N. N., \& Minetto, M. de F. (2017). O paradigma inclusivo e a educação infantil: qualidade no atendimento e promoção do desenvolvimento. Texto recuperado em 10 jul. 2018: http://omnipax.com.br/livros/2017/DCFES/dcfes-cap8.pdf

Sucuoglu, B., Bakkaloglu, H., Karasu, F. I., Demir, S., \& Akalin, S. (2014). Preschool teachers' knowledge levels about inclusion. Educational Sciences: Theory \& Practice, 14(4), 1477-1483. DOI: 10.12738/estp.2014.4.2078

Vitta, F. C. F. (2010). A inclusão da criança com necessidades especiais na visão de berçaristas. Cadernos de Pesquisa, 40(139), 75-93. DOI: 10.1590/S0100-15742010000100005

Winnicott, D. W. (1982). A criança e o seu mundo (A. Cabral, trad.). Rio de Janeiro: LTC Editora. (Trabalho original publicado em 1957).

Winnicott, D. W. (1984). Consultas terapêuticas em psiquiatria infantil (J. M. X. Cunha, trad.). Rio de Janeiro. Imago. (Trabalho original publicado em 1971).

Winnicott, D. W. (1988). A mãe dedicada comum. In: D.W.Winnicott, Os bebês e suas mães (J. L. Camargo, trad., pp.1-11). São Paulo: Martins Fontes. (Trabalho original publicado em 1966). 
Winnicott, D. W. (1990). Estabelecimento da relação com a realidade externa. In: D.W.Winnicott. Natureza Humana (D. Bogomoletz, trad., pp.120-135). Rio de Janeiro: Imago. (Trabalho original publicado em 1988).

Winnicott, D. W. (1993). A família e o desenvolvimento individual (M. B. Cipolla, trad.). São Paulo: Martins Fontes. (Trabalho original publicado em 1965).

Winnicott, D. W. (1997). A professora, os pais e o médico. In: D.W.Winnicott, Pensando sobre crianças (M. A. V. Veronese, trad., pp.89-100). Porto Alegre: Artes Médicas. (Trabalho original publicado em 1936).

Winnicott, D. W. (2000). Desenvolvimento emocional primitivo. In: D.W.Winnicott, Da pediatria à psicanálise (D. Bogomoletz, trad., pp.218-232). Rio de Janeiro: Imago. (Trabalho original publicado em 1945).

Zucchetti, D. T. (2011). A inclusão escolar vista sob a ótica de professores da escola básica. Educação em Revista, 27(2), 197-218. doi: 10.1590/S0102-46982011000200010

Recebido em junho/2019 - Aceito em agosto/2019. 